\title{
Opportunities to Improve Academic Research Through Open Research Practices
}

\section{Devin R. Berg}

University of Wisconsin-Stout www.devinberg.com

@devinberg

DOI: 10.6084/m9.figshare.6291668

June 4-6, 2018 
University of Wisconsin-Stout

Design, robotics, medical devices

Engineering education and practice

Open engineering 
WHAT

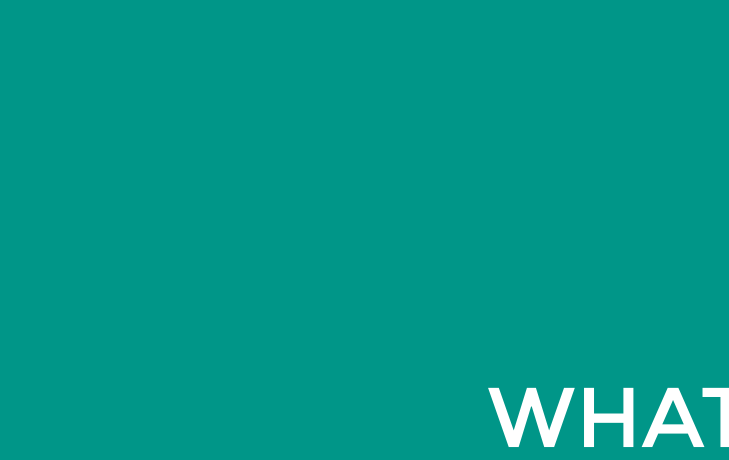


What is open research?

The rules are simple

Make the work accessible 
What do you mean accessible?

Accessible is obtainable

Accessible is understandable

Accessible is reproducible

Accessible is inclusive 
There is no wrong way to be open

Find the level of open that works

There is a community out there willing to help! 
WHY 
To have an impact! 


\section{People can't access the work}

Many institutions do not have subscriptions

Non-academics can't understand the work

Motivated individuals can't recreate the work 


\section{Everyone has the right freely to participate in the cultural life of the community, to enjoy the arts and to share in scientific advancement and its benefits.}




\section{...to aid in diffusing \\ among the people of the United States useful and, practical information...}

Morrill Land-Grant Act, 1862; Smith-Lever Act, 1914 


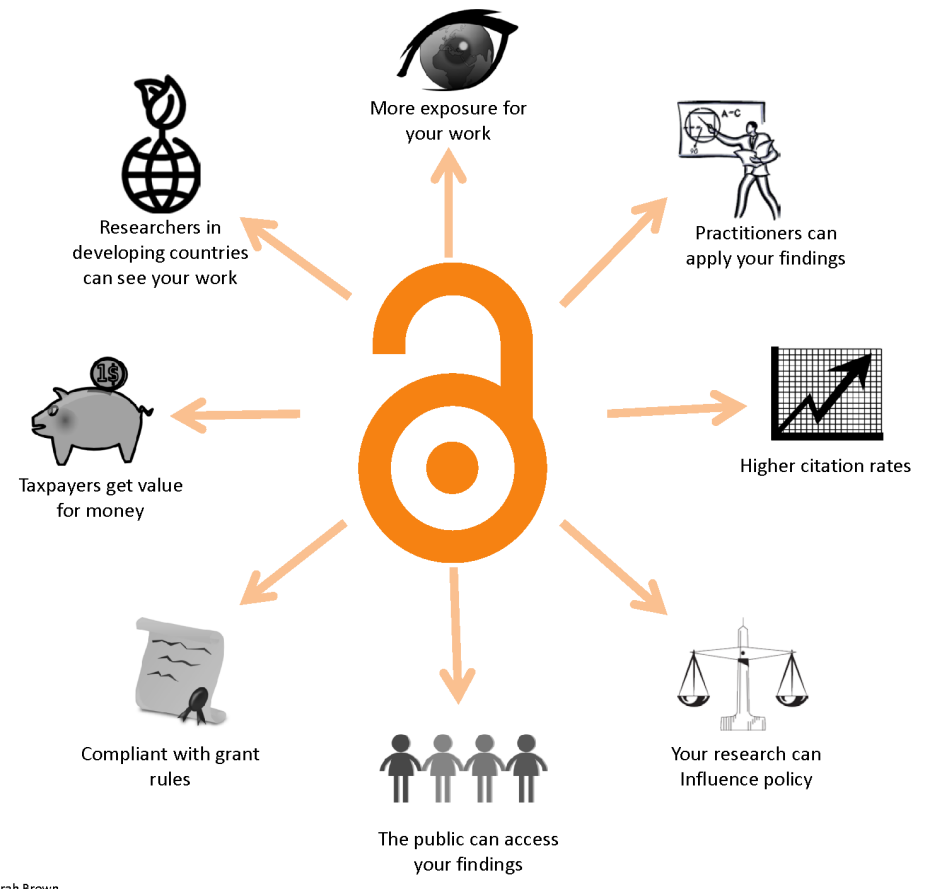


(1)

\section{HOW \\ . \\ HOW}

, 
Make the work obtainable

Make the work understandable

Make the work reproducible

Make the work inclusive 
Preprint and self-archive, publish OA

\author{
Use accessible language
}

Use reproducible workflows

Include diverse perspectives 


\section{There are many resources available}




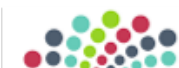

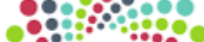

9::

\%

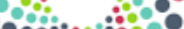

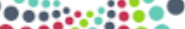

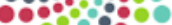

\%웅
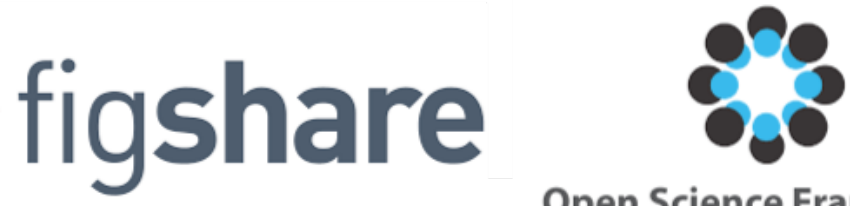

Open Science Framework
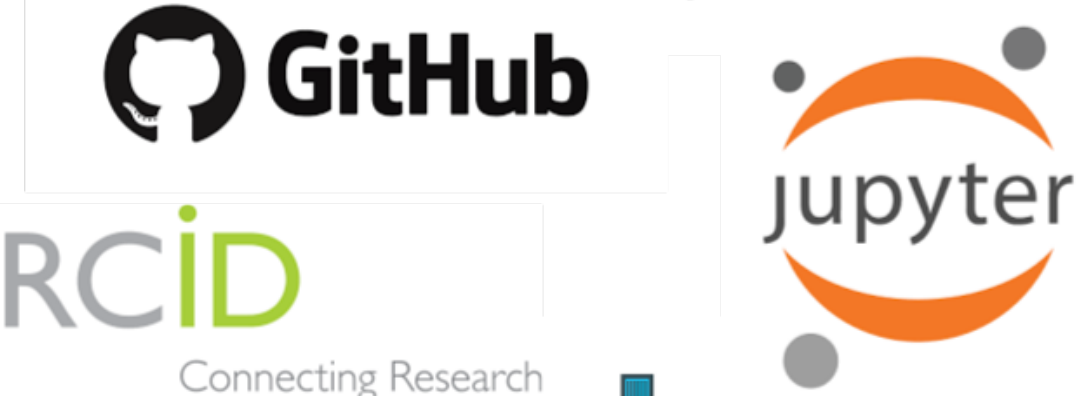

Connecting Research and Researchers

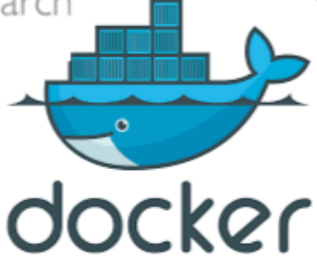




\section{The Journal of} Open Engineering

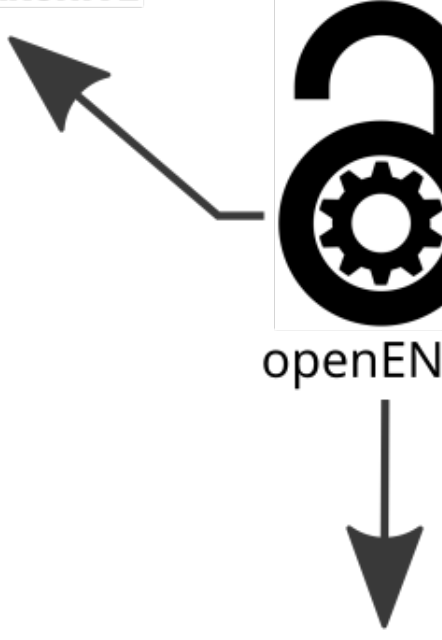

Open Educational Resources? 


\title{
Examples
}

\section{Open practices can lead to some amazing outcomes}

\author{
Everything from hardware to \\ software to workflows.
}




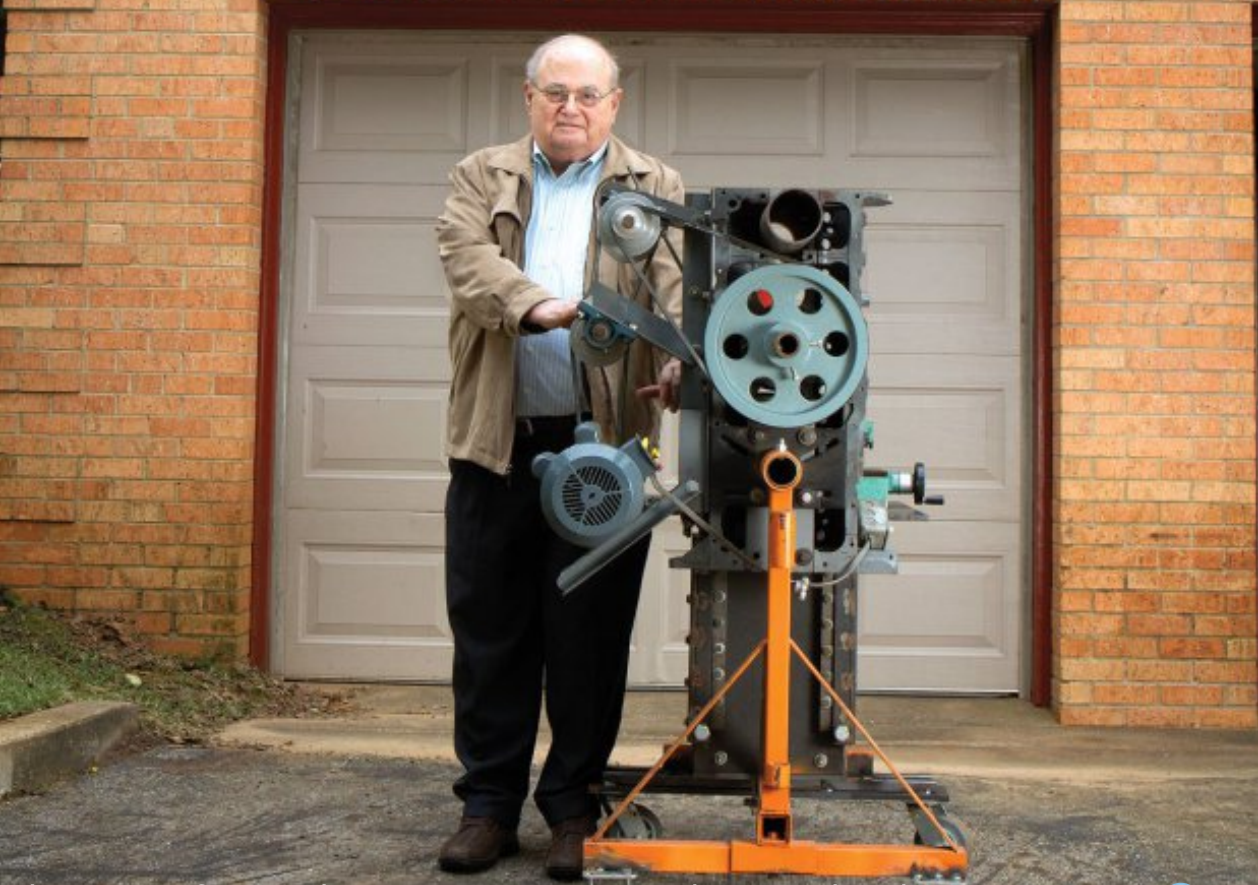

The Story of Pat Delany, Open Source Machine Tools Advocate 


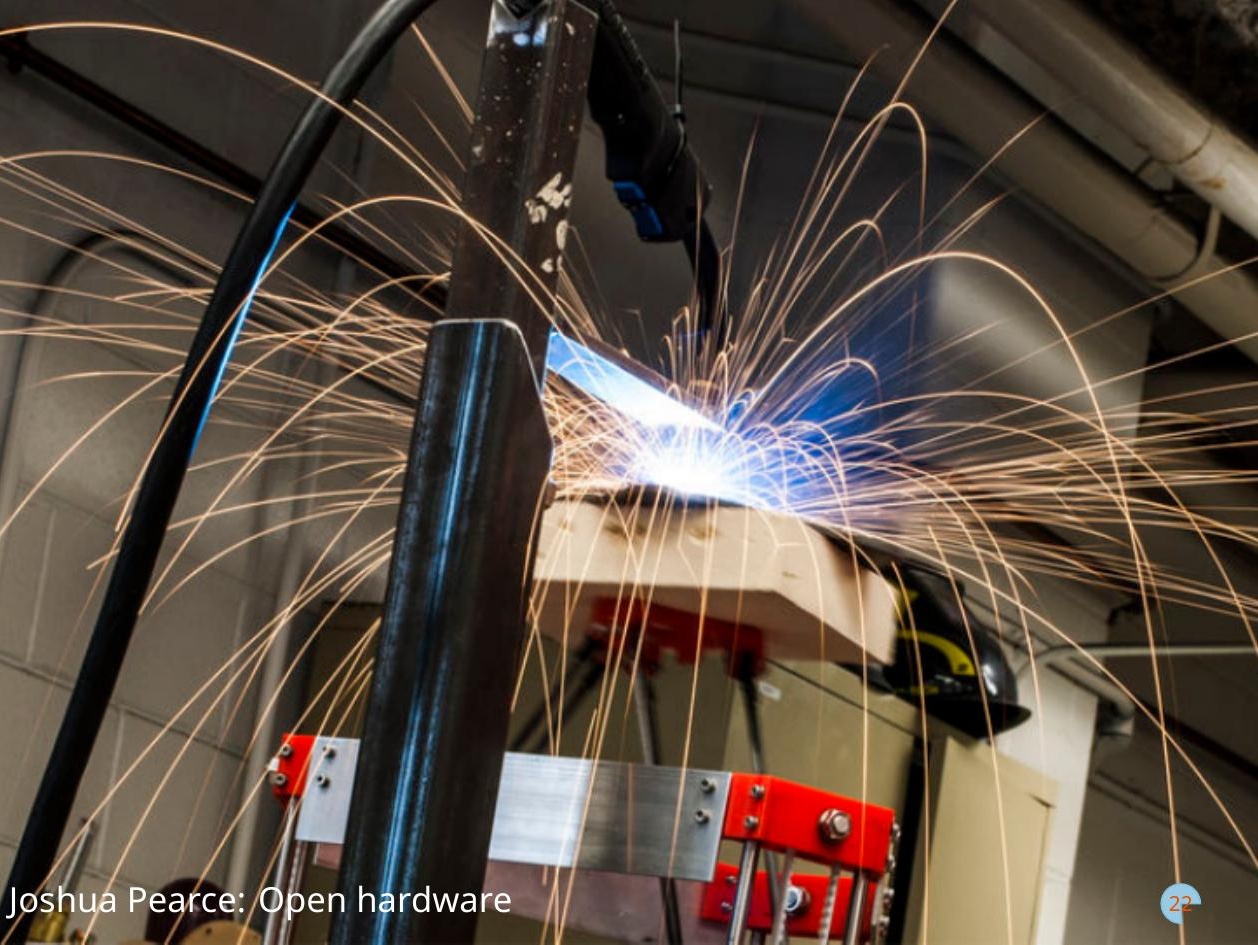




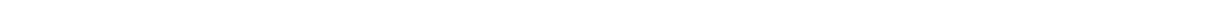

GliaX Stethoscope; Image 


\section{But what about patents? ${ }^{1}$}

Of course the rules of prior art still apply

\section{In the US, preprinting may help establish priority}

\section{Is patenting the best route to having an impact?}




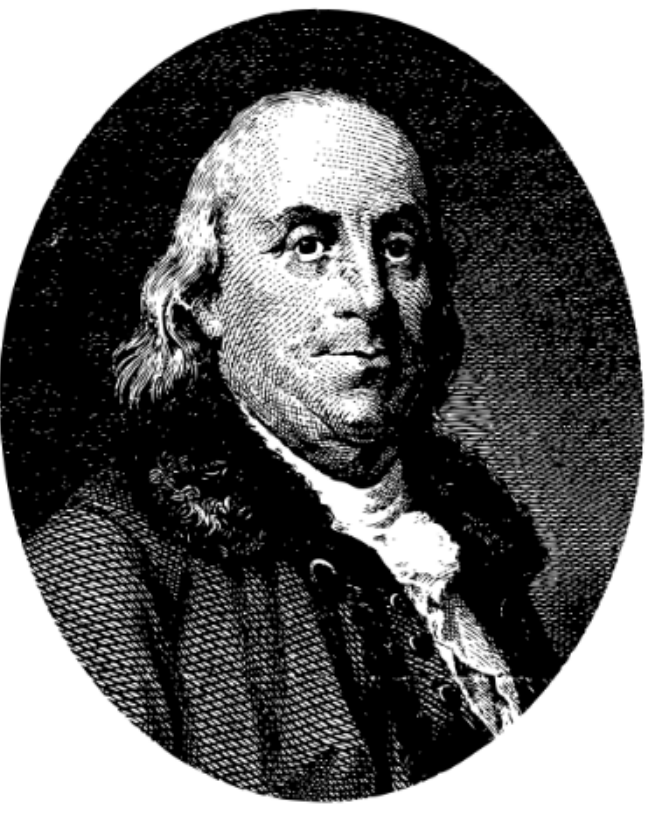

"As we enjoy great advantages from the inventions of others, we should be glad of an opportunity to serve others by any invention of ours, and this we should do freely and generously." 


\section{Barriers to adoption}

\section{Need for training and updated workflows}

\section{Career reward structures}

Pressures of capitalism 
Opportunities to support open

(broadly)

\section{Create an institutional mandate}

Use tech transfer offices to push for greater impact

Empower and fund university libraries to help

Support training in open practices

DOI: 10.12688/f1000research.14593.1 
Opportunities to support open

\section{(specifically)}

Consider accessibility and impact of research products in T\&P guidelines

Recognize contributions of software and data alongside publications

Reduce importance of "traditional" venues 


\section{Guiding Principles}

\section{Budapest Open Access Initiative}

\section{Declaration on Research Assessment}

\section{FAIR Data Principles}




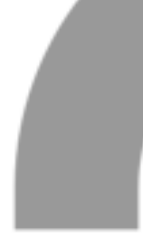

